\title{
Computational fluid dynamics analysis on the course stability of a towed ship
}

\section{A. Fitriadhy*, M.K. Aswad, N. Adlina Aldin, N. Aqilah Mansor, A.A. Bakar, and W.B. Wan Nik}

\author{
${ }^{1}$ Program of Maritime Technology, School of Ocean Engineering, \\ Universiti Malaysia Terengganu, Malaysia. \\ *Email: naoe.afit@ gmail.com \\ Phone: +6096683856; Fax: +6096683193
}

\begin{abstract}
Due to the highly complex phenomenon of a ship towing system associated with the presence of a dynamic nonlinear towline tension, a reliable investigation allowing for an accurate prediction of the towed ship's course stability is obviously required. To achieve the objective, a Computational Fluid Dynamic simulation approach is proposed by investigating attainable and precise course stability outcomes, whilst a hydrodynamic description underlying the rationale behind the results is explained. Several towing parameters such as various towline lengths and tow point locations with respect to the centre of gravity of the barge have been taken into account. Here, tug and barge is employed in the simulation as the tow and towed ship, respectively. In addition, a towing velocity is constantly applied on the tug. The results revealed that the course stability of the towed ship increases in the form of more vigorous fishtailing motions as the towline length subsequently increases from 1.0 to 3.0. Meanwhile, the increase of tow point location from 0.5 to 1.0 leads to a significant improvement in the course stability of the towed ship, as indicated by the reduction of the sway and yaw motions by $227 \%$ and $328 \%$, respectively. It is concluded that the increase of tow point location is a recommended decision to achieve a better towing course stability for the barge.
\end{abstract}

Keywords: CFD; course stability; towline length; tow point; towline tension.

\section{INTRODUCTION}

Recognising the inherent advantages offered by the typical ship towing system, it has become frequently used in inland waterway/ocean transportation, military operations and in the salvage of disabled ships [1]. In this transportation mode, an improper towing system may introduce severe towing instability and directly lead to accidents such as collisions with other vessel or onshore structures which may probably occur, especially in confined waters with high sea traffic. Additionally, this type of accident may often lead to loss of property, human lives and environmental issues [2]. An extensive investigation regarding the course stability of the towed ship is therefore required. Several researchers have presented many theoretical approaches to analyse the course stability of the ship's towing system. [3] proposed a numerical theory of barge dynamic stability in towing operations with and without the presence of skegs. Then, [4], [5] and [6] developed numerical simulations where the effects of the towline length and tow point locations to the course stability of a towed ship have been addressed. [7], [8] and [9] performed numerical analyses of towed ships' stability in steady winds. Furthermore, experimental 
model tests have been conducted at Towing-Tank to investigate the course stability of a tanker as the towed ship in [10] and [11]. In particular, this approach is relatively expensive, time-consuming and even impractical for various tests on the ship's towing system. To accommodate such demands, a proper simulation approach aimed at gaining reliable predictions on the course stability of the ship towing system as compared to analytical/numerical approaches is needed.

This paper presents a CFD simulation used to predict the course stability of a towed ship in calm waters. Here, the commercial CFD called FLOW3D version 10.1 is utilised by applying the incompressible unsteady Reynolds-Averaged Navier Stokes equations (RANS) in simulation, in which both the RANS equation and continuity equations are discretised using the finite volume method based on Volume of Fluid (VOF) to deal with the nonlinear free surface. In addition, the computational domain with adequate numbers of grid meshes specifically for the towed ship model has been carefully determined before the simulations. Basically, this is solved by the means of a mesh independent study conducted to select the optimal domain discretisation. Several parameters such as various towline lengths ratios $\left(\ell^{\prime}=\ell / L\right)$ from 1.0 up to 3.0 and tow point locations $\left(\ell_{b}^{\prime}=\ell_{b} / L\right)$ from 0.5 up to 1.0 are taken into consideration. The results are comprehensively discussed to point out the effect of towline lengths and tow point locations with their dependencies on the course stability of the towed ship, which is presented in the form of sway and yaw motions. Correspondingly, the towline tension is also captured and properly explained with regard to the aforementioned parametric studies.

\section{METHODS AND MATERIALS}

\section{Governing Equations}

The CFD flow solver in FLOW-3D version 10.1 is based on the incompressible unsteady RANS equations in which the solver applies the Volume of Fluid (VOF) to track the free surface elevation. The interface between fluid and solid boundaries is simulated using the fractional area volume obstacle representation favour method. This method computes the open area and volume in each cell to define the area that is occupied by the obstacle.

\section{Continuity and Momentum Equations}

The continuity and momentum equations for a moving object and the relative transport equation for VOF function are [12]:

$$
\begin{gathered}
\frac{V_{f}}{\rho} \frac{\partial \rho}{\partial t}+\frac{1}{\rho} \nabla \cdot\left(\rho \vec{u} A_{f}\right)=-\frac{\partial V_{f}}{\partial t} \\
\frac{\partial \vec{u}}{\partial t}+\frac{1}{V_{f}}\left(\vec{u} A_{f} \cdot \nabla \vec{u}\right)=-\frac{1}{\rho}\left[\nabla{ }_{\rho}+\nabla \cdot\left(\tau A_{f}\right)\right]+\vec{G} \\
\frac{\partial F}{\partial t}+\frac{1}{V_{f}} \nabla \cdot\left(F \vec{u} A_{f}\right)=-\frac{F}{V_{f}} \frac{\partial V_{f}}{\partial t}
\end{gathered}
$$

where $\rho$ is the density of the fluid, $\vec{u}$ is the fluid velocity, $V_{f}$ is the volume fraction, $A_{f}$ is the area fraction, $p$ is the pressure, $\tau$ is the viscous stress tensor, $G$ denotes gravity, and $F$ is the fluid fraction.

In the case of the coupled General Moving Object's (GMO) motion, Eqs. (1) and (2) are solved at each time step, the location of all moving objects recorded, and the area 
and volume fractions updated using the FAVOR technique. Equation (3) are solved with the source term $-\frac{\partial V_{f}}{\partial t}$ on the right-hand side, which is computed as

$$
-\frac{\partial V_{f}}{\partial t}=\vec{U}_{o b j} \cdot \vec{n} S_{o b j} / V_{c e l l}
$$

where $S_{o b j}$ is the surface area, $\vec{n}$ surface normal vector, $\vec{U}_{o b j}$ is the velocity of the moving object at a mesh cell, and $V_{\text {cell }}$ is the total volume of the cell [12].

\section{Turbulence Model}

The transport equation for $k_{T}$ includes the convection and diffusion of the turbulent kinetic energy, the production of turbulent kinetic energy due to shearing and buoyancy effects, diffusion, and dissipation due to viscous losses within the turbulent eddies. Buoyancy production only occurs if there is a non-uniform density in the flow, and includes the effects of gravity and non-inertial accelerations. The transport equation is:

$$
\frac{\partial k_{T}}{\partial t}+\frac{1}{V_{F}}\left\{u A_{x} \frac{\partial k_{T}}{\partial x}+v A_{y} \frac{\partial k_{T}}{\partial y}+w A_{z} \frac{\partial k_{T}}{\partial z}\right\}=P_{T}+G_{T}+\text { Diff }_{k_{T}}-\varepsilon_{T}
$$

where $V_{F}, A_{x}, A_{y}$ and $A_{z}$ are FLOW-3D's FAVOR ${ }^{\mathrm{TM}}$ functions, and $P_{T}$ is the turbulent kinetic energy production:

$$
P_{T}=\operatorname{CSPRO}\left(\frac{\mu}{p V_{F}}\right)\left\{\begin{array}{l}
2 A_{x}\left(\frac{\partial u}{\partial x}\right)^{2}+2 A_{y}\left(R \frac{\partial v}{\partial y}+\zeta \frac{u}{x}\right)^{2}+2 A_{z}\left(\frac{\partial w}{\partial z}\right)^{2} \\
+\left(\frac{\partial v}{\partial x}+R \frac{\partial u}{\partial y}+\zeta \frac{v}{x}\right)\left[A_{x} \frac{\partial v}{\partial x}+A_{y}\left(R \frac{\partial u}{\partial y}+\zeta \frac{v}{x}\right)\right]+\left(\frac{\partial u}{\partial z}+\frac{\partial w}{\partial x}\right)\left(A_{z} \frac{\partial u}{\partial z}+A_{x}\left(R \frac{\partial w}{\partial x}\right)\right. \\
+\left(\frac{\partial v}{\partial z}+R \frac{\partial w}{\partial y}\right)\left(A_{z} \frac{\partial v}{\partial z}+A_{y} R \frac{\partial w}{\partial y}\right)
\end{array}\right\}
$$

where CSPRO is a turbulence parameter.

In the case of turbulent conditions, the $k-\varepsilon$ model is proposed where $k_{T}$ and $\varepsilon_{T}$ are the turbulent kinetic energy and turbulent dissipation energy, respectively. Two transport equations for the turbulent kinetic energy $k_{T}$ and its dissipation $\varepsilon_{T}$ which is so-called the $k-\varepsilon$ model is used in the computational simulation. It is reasonable since this equation model provides more reliable approximations to many types of flows [12] .In addition, the $k-\varepsilon$ model is quite economical in terms of CPU time, compared to for example the SST turbulence model, which increases the required CPU time by nearly $25 \%$. [12] [13, 14] stated that the $k-\varepsilon$ model reduces computational time and resources by reducing the number of nodes in the near wall regions, thus allowing for more probing simulation and trial geometries.

\section{Body Motion Computation}

The body motion is analysed in a space-fixed Cartesian coordinate system which is a part of the global coordinate system. The governing equation of the six degree of freedom (DOF) of a rigid body motion can be expressed in this coordinate system as

$$
\begin{aligned}
& \frac{d}{d t}\left(m \vec{v}_{C}\right)=\vec{f} \\
& \frac{d}{d t}\left(M_{C} \cdot \vec{\omega}_{C}\right)=\vec{m}_{C}
\end{aligned}
$$


Index $\mathrm{C}$ denotes the centre of mass of the body, m denotes the mass of the body, $\vec{v}_{c}$ the velocity vector, $M_{c}$ is the tensor of the moments of inertia, $\vec{\omega}_{\mathrm{c}}$ is the angular velocity vector, $\vec{f}$ denotes the resulting force vector, and $\vec{m}_{\mathrm{c}}$ denotes the resultant moment vector acting on the body [15] [16]. The resultant force $\vec{f}$ has three components; surface force, field forces and external forces:

$$
\vec{f}=\int_{S}(T-\rho I) \cdot \vec{n} d S+\int_{V} \rho_{b} \vec{b} d V+\vec{f} E
$$

Here, $\rho_{b}$ is the density of the body. The only field force considered is gravity, so the volume integral of above equation (right hand side) is reduced to $m \vec{g}$, where $g$ is the gravity acceleration vector. The vector $f \vec{E}$ denotes the external forces acting in the body [2].

\section{Simulation Conditions}

\section{Principal Data of Ship}

The principal dimensions of the tug and barge, called the $2 \mathrm{~B}$ used in the simulations are presented in Table 1, while its body plan is shown in Figure 1. A constant speed of 7.0 knots was employed on the tug.

\section{Parametric Studies}

Referring to Table 2, the different towline lengths from $\ell^{\prime}=1.0$ up to 3.0 are used in the computational simulations where the location of the tow point is set at $\ell^{\prime}{ }_{b}=0.5$.

Table 1. Principal dimensions of barge 2B and tug

\begin{tabular}{lcccc}
\hline \multirow{2}{*}{ Description } & \multicolumn{2}{c}{ 2B } & \multicolumn{2}{c}{ Tug } \\
\cline { 2 - 5 } \multicolumn{1}{c}{ Length, $L(m)$} & 60.960 & 1.219 & 40.000 & 0.800 \\
Breadth, $B(m)$ & 21.340 & 0.426 & 9.000 & 0.178 \\
Draft, $d(m)$ & 2.740 & 0.055 & 2.200 & 0.044 \\
Volume, $\left(m^{3}\right)$ & 3292.400 & 0.026 & 494.700 & 0.0003 \\
$L / B$ & 2.860 & 2.860 & 4.440 & 4.440 \\
Block coefficient,$C_{b}$ & 0.920 & 0.920 & 0.630 & 0.630 \\
$k_{\text {yy } 2} / L$ & 0.252 & 0.252 & 0.250 & 0.250 \\
$X_{\text {Gabaft the misship }},(m)$ & -1.040 & -0.021 & -2.230 & -0.046 \\
Velocity, $V_{s}(m / s)$ & & & 3.602 & 0.413 \\
\hline
\end{tabular}

Table 2. Various towline lengths from $\ell^{\prime}=1.0$ to 3.0

\begin{tabular}{cc}
\hline Towline length $\left(\ell^{\prime}\right)$ & Tow point $\left(\ell_{\mathrm{b}}^{\prime}\right)$ \\
\hline 1.0 & \\
2.0 & 0.5 \\
3.0 & \\
\hline
\end{tabular}

In addition, the various locations of the tow points with respect to the location of the centre of gravity for the barge $2 \mathrm{~B}\left(\ell^{\prime}{ }_{b}=\ell_{b} / \mathrm{L}\right)$ are presented in Table 3 . In this case, the towline length is constant at $\ell^{\prime}=2.0$. 

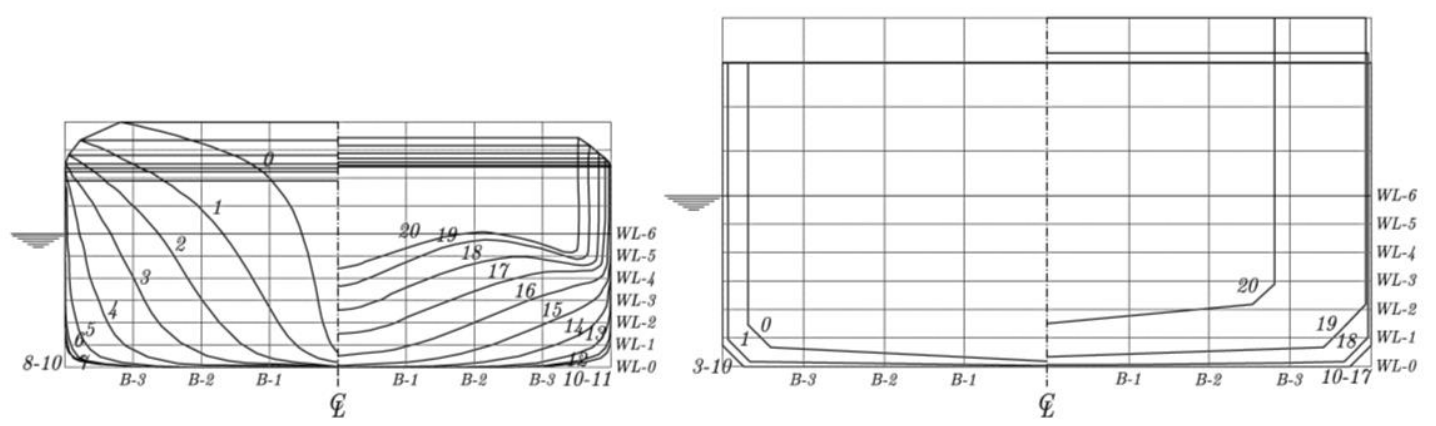

Figure 1. Body plan of tug (left) and barge (right).

Table 3: Various tow points from $\ell^{\prime}=0.5$ up to 1.0

\begin{tabular}{cl}
\hline Towline length $\left(\ell^{\prime}\right)$ & \multicolumn{1}{c}{ Tow point $\left(\ell^{\prime}{ }_{b}\right)$} \\
\hline & 0.5 \\
2.0 & 0.75 \\
& 1.0 \\
\hline
\end{tabular}

\section{Computational Domain and Boundary Conditions}

The computational domain uses a structured mesh that is defined in a Cartesian. Referring to Figure 2, the boundary condition was marked in the mesh block. The boundary condition at the X-max boundary is specified velocity so that there is flow of water. In order to save computational time, a velocity of $0.413 \mathrm{~m} / \mathrm{s}$ is given to the water at the $\mathrm{X}$ max boundary. For X-min, Y-max and Y-min outflow are used to prevent reflection, while Z-min and Z-max use symmetry. The boundary conditions for this simulation are as shown in Table 4.

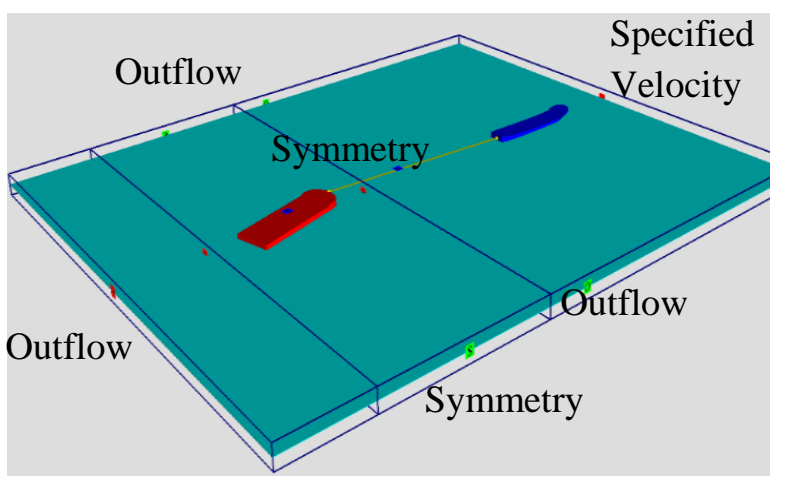

Figure 2. Boundary conditions.

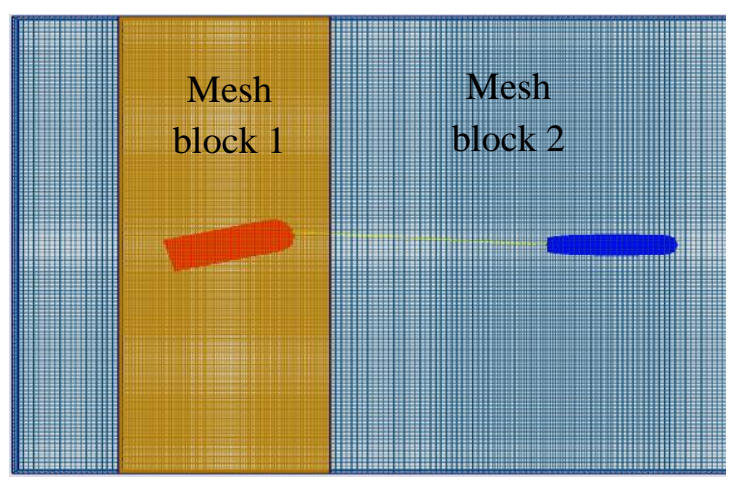

Figure 3. Meshing generation.

The tug and barge are coupled together using a towline. The barge is inclined by $15^{\circ}$ with respect to the initial z-axis. The tug which acts as the tow ship was assigned as the prescribed motion, while the barge as the towed ship was set as the coupled motion in the X-translational, Y-translational and Z-rotational motions (surge, sway and yaw motions). The towline is set as a massless elastic rope with a spring coefficient of 2.0 $\mathrm{N} / \mathrm{m}$. Based on the FLOW3D v10.1.1, the average duration of every simulation was about 70-80 hours (4 parallel computations) on a HP Z820 workstation PC with processor Intel (R) Xeon (R) CPU ES-2690 v2 @ 3.00 GHz (2 processors) associated with an installed memory [16] of $32.0 \mathrm{~GB}$ and a 64-bit Operating System. 
Table 4. Boundary conditions.

\begin{tabular}{ccc}
\hline Boundary & \multicolumn{2}{c}{ Condition } \\
\cline { 2 - 3 } & Mesh block 1 & Mesh block 2 \\
\hline $\mathrm{X}_{\min }$ & Outflow & Symmetry \\
$\mathrm{X}_{\max }$ & Specified Velocity & Symmetry \\
$\mathrm{Y}_{\min }$ & Outflow & Symmetry \\
$\mathrm{Y}_{\max }$ & Outflow & Symmetry \\
$\mathrm{Z}_{\min }$ & Symmetry & Symmetry \\
$\mathrm{Z}_{\max }$ & Symmetry & Symmetry \\
\hline
\end{tabular}

\section{Mesh Independent Study}

A mesh independent study is necessary for examining the adequate number of meshes needed in order to ensure the accuracy of computation results. Table 5 shows the result of the mesh independent study. The total number of cells was about 3,862,500 in case C. It was then selected as it has reasonable CFD solution accuracy and is associated with less computational time. Table 5 shows the mesh independent study of the system, tow $\operatorname{point}\left(\ell_{b}^{\prime}=0.5\right)$, towline length $\left(\ell^{\prime}=2.0\right)$ and $V s=0.413 \mathrm{~m} / \mathrm{s}$ in calm waters.

Table 5. Mesh independent study.

\begin{tabular}{ccc}
\hline Case & Total number of real cells & Maximum Towline tension $(\mathrm{N})$ \\
\hline A & $1,475,712$ & 1.9061736 \\
B & $2,513,722$ & 1.9138827 \\
C & $3,862,500$ & 1.8969411 \\
D & $5,094,044$ & 1.8950994 \\
\hline
\end{tabular}

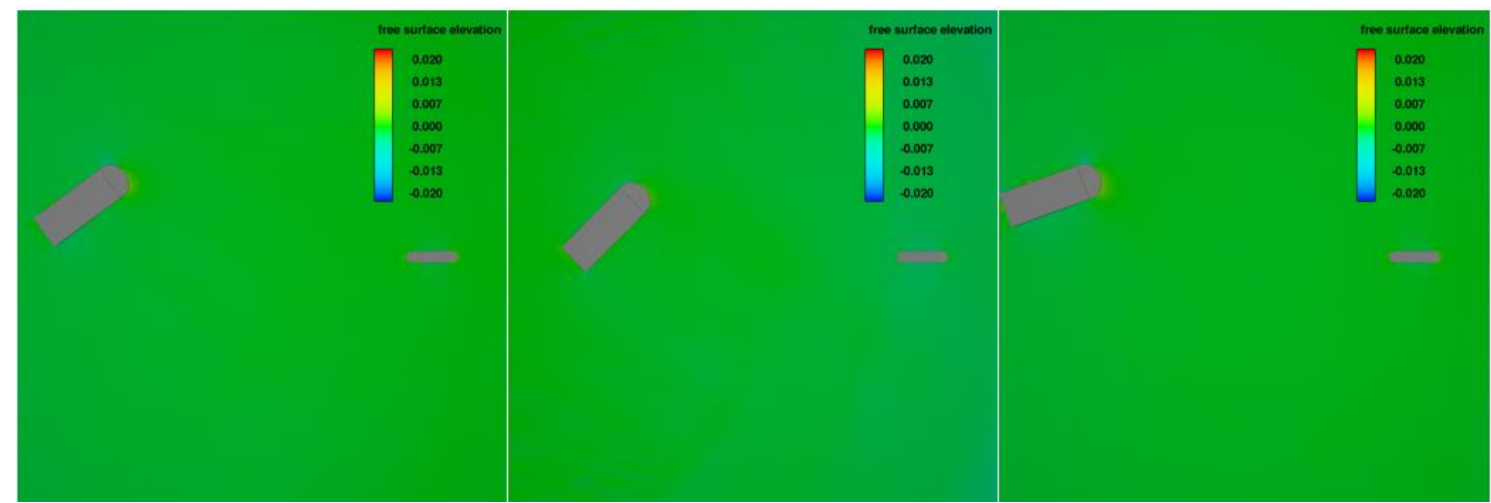

Figure 4. Example of CFD visualization using $2 \mathrm{D}$ views $\left(\ell^{\prime}{ }_{b}=0.5, \ell^{\prime}=2.0\right.$, and

$$
V s=0.413 \mathrm{~m} / \mathrm{s}) \text {. }
$$

A meshing generation is created in Flow3D v10.1 as shown in Figure 3. In this study, an extra refinement of the mesh, so-called the nested-block is added to locally increase the meshing resolution [16] [17]. Here, the cell sizes are 0.02 and 0.01 in mesh blocks 1 and 2, respectively. 


\section{RESULTS AND DISCUSSION}

Figures 5-8 show that the CFD simulations have been successfully carried out to predict the course stability of the towing system at various towline lengths and tow point locations. The simulation's sway and yaw motions associated with the towline tension are discussed accordingly.

\section{Effect of Towline Length}

Figure 5 shows the characteristics of the sway and yaw motions and the dynamic towline tension at various towline lengths from $\ell^{\prime}=1.0$ to 3.0. Extending the towline length $\ell^{\prime}$ from 1.0 to 2.0 and 3.0 had resulted in an increase of sway motion of the towed ship by $41.6 \%$. This unstable towing mainly occurred due to the unwieldy amplitude of her heading angle and yaw rate associated with the spacious amplitude of her fishtailing motion. On the other hand, the slewing/fishtailing period of 2B was lower by $10 \%$ as $\ell^{\prime}$ was increased from 1.0 to 3.0. Similar to what was reported by Fitriadhy et al. [6], the increment of towline length had relatively smaller influence on the entire amplitude motion performance of the barge. Although the increase of towline lengths was insignificant in reducing the sway motions, the course stability of the $2 \mathrm{~B}$ had improved as commented on in Fitriadhy and Yasukawa [4]. Correspondingly, the maximum tension force had decreased by $7.8 \%$ as $\ell^{\prime}$ was increased from 1.0 to 3.0. Regardless of the maximum value of the free surface elevation, the reason can be explained by the fact that the $2 \mathrm{~B}$ experienced more vigorous sway motions when the shorter towline length was employed (see Figure 6).
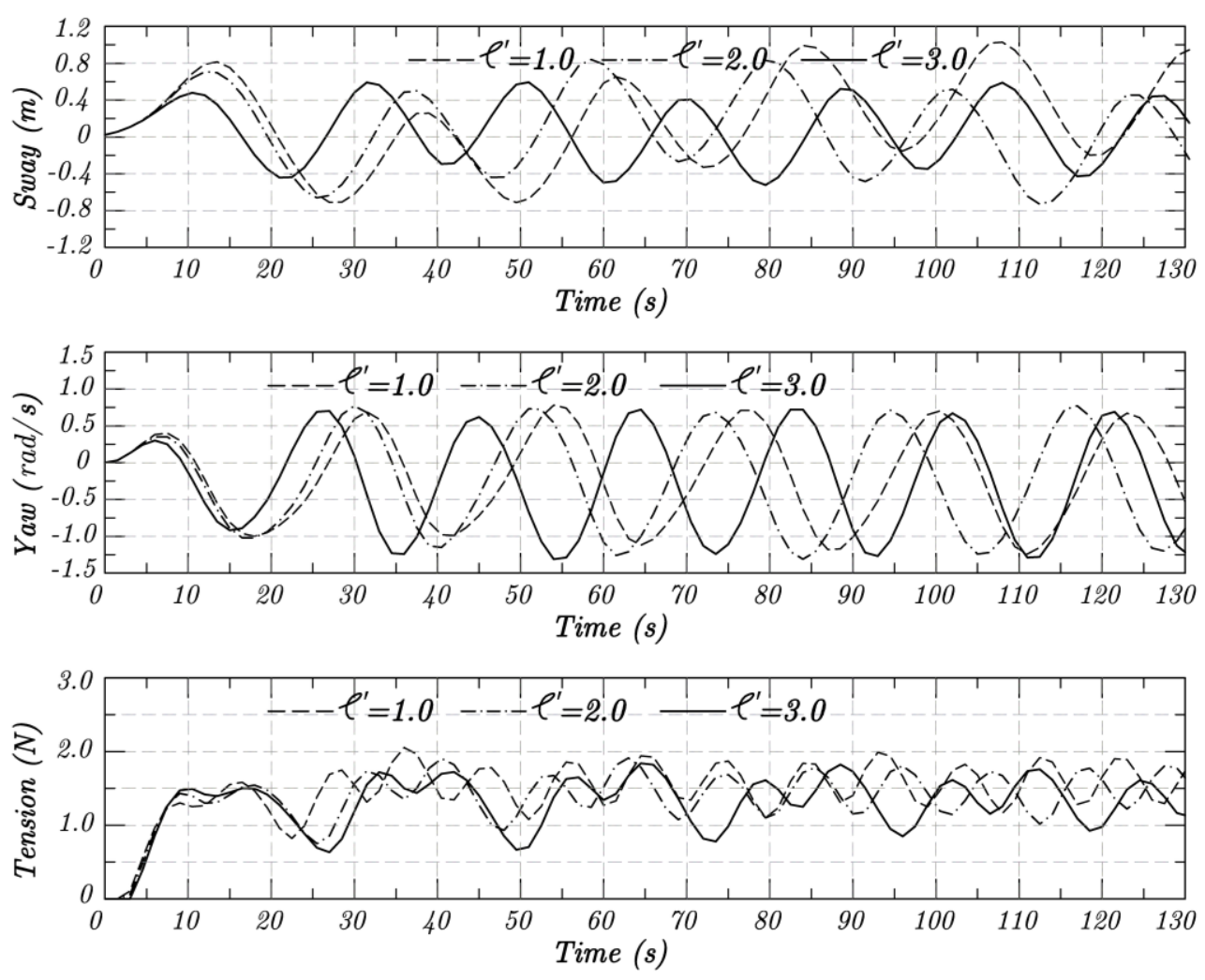

Figure 5. Characteristics of 2B's sway and yaw motions associated with towline tension at various towline lengths 


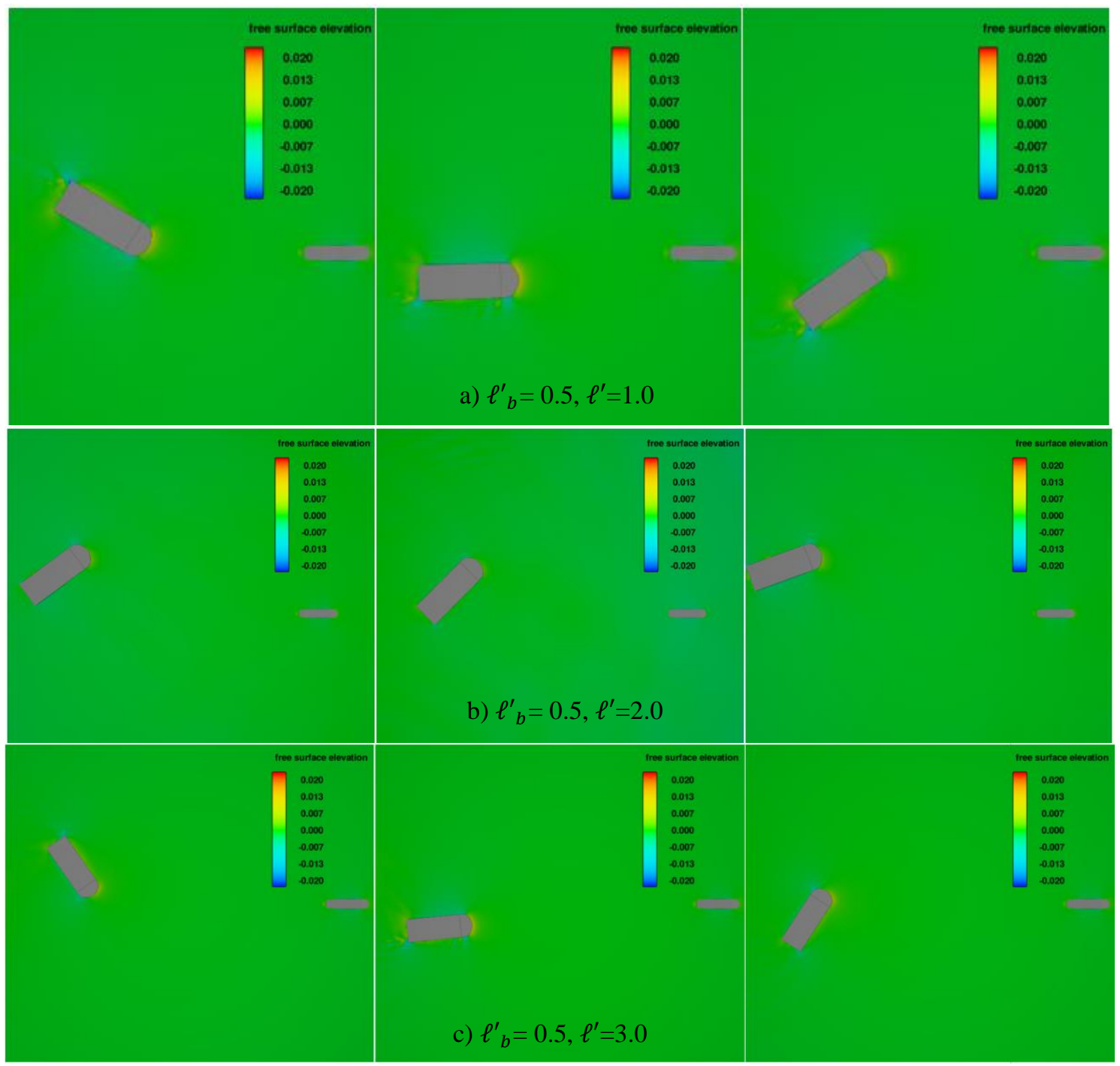

Figure 6. Free surface elevation, $\ell^{\prime}{ }_{b}=0.5, \ell^{\prime}=1.0(\mathrm{a}), \ell^{\prime}=2.0(\mathrm{~b}), \ell^{\prime}=3.0(\mathrm{c})$, $V s=0.413 \mathrm{~m} / \mathrm{s}$.

\section{Effect of Tow Point Location}

The characteristics of the sway and yaw motions associated with the dynamic towline tension at various tow point locations are displayed in Figure 7. Similar to what was remarked in the numerical simulation by Fitriadhy et al. [5], the subsequent increase of tow points $\ell^{\prime}{ }_{b}$ from 0.5 to 0.75 and 1.0 had resulted in the significant reduction of the sway and yaw motions. It is noted here that the yaw motion decreased by $87.67 \%$ and $128 \%$ as $\ell^{\prime}{ }_{b}$ is increased from 0.5 to 0.75 and 0.75 to 1.0 , respectively. Inherently, the course stability of 2B had notably improved. Meanwhile, the existence of this favourable effect had sufficiently led to an attenuation of the dynamic towline tension. Evidently, the increase in the tow point is an effective way of recovering the towing instability and indeed, may prevent the towline's breakage [18]. Referring to Figure 8, the presence of higher waves at the bow region of $2 \mathrm{~B}$ with $\ell^{\prime}=1.0$ was proportional with the higher resistance (high pressure) which inherently reduced her sway and yaw motions. These will decrease the unwieldy slewing motion and lead to better course stability, as noted by Fitriadhy and Yasukawa [4]. 

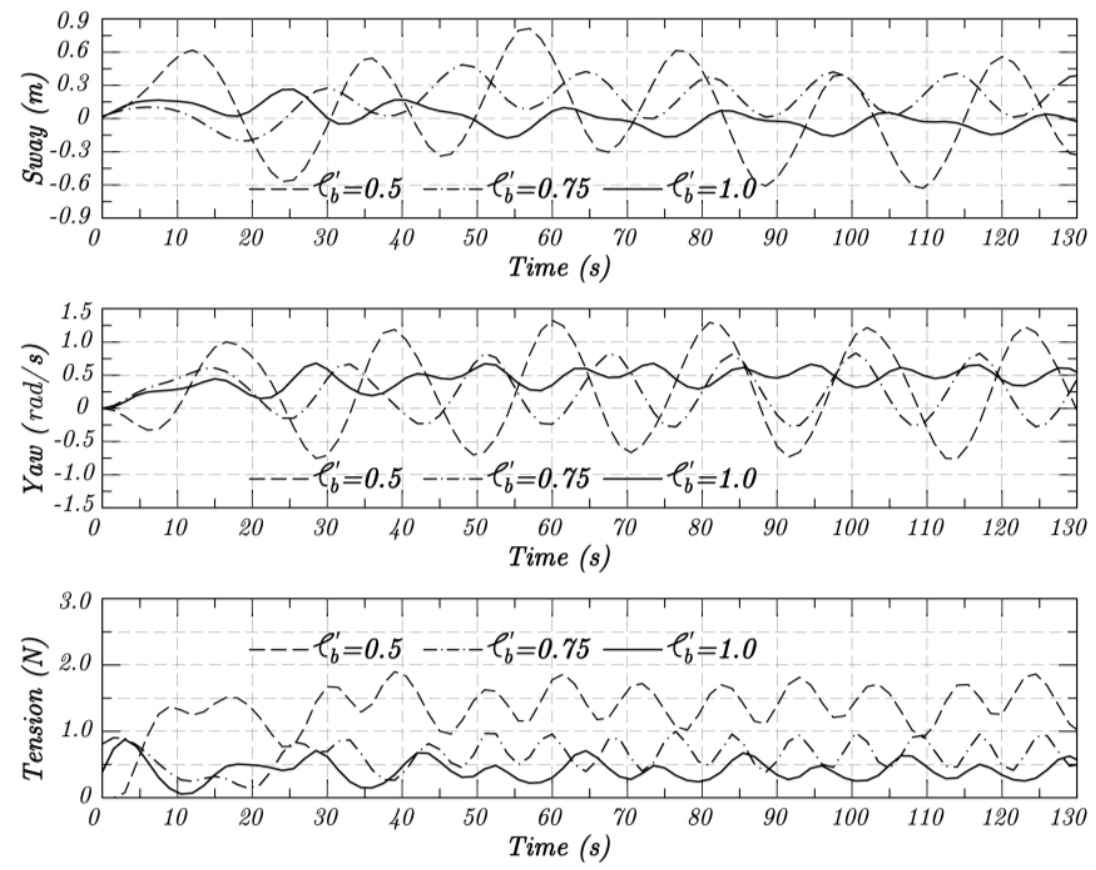

Figure 7. Characteristics of sway and yaw motions of $2 \mathrm{~B}$ associated with towline tension at various tow points.

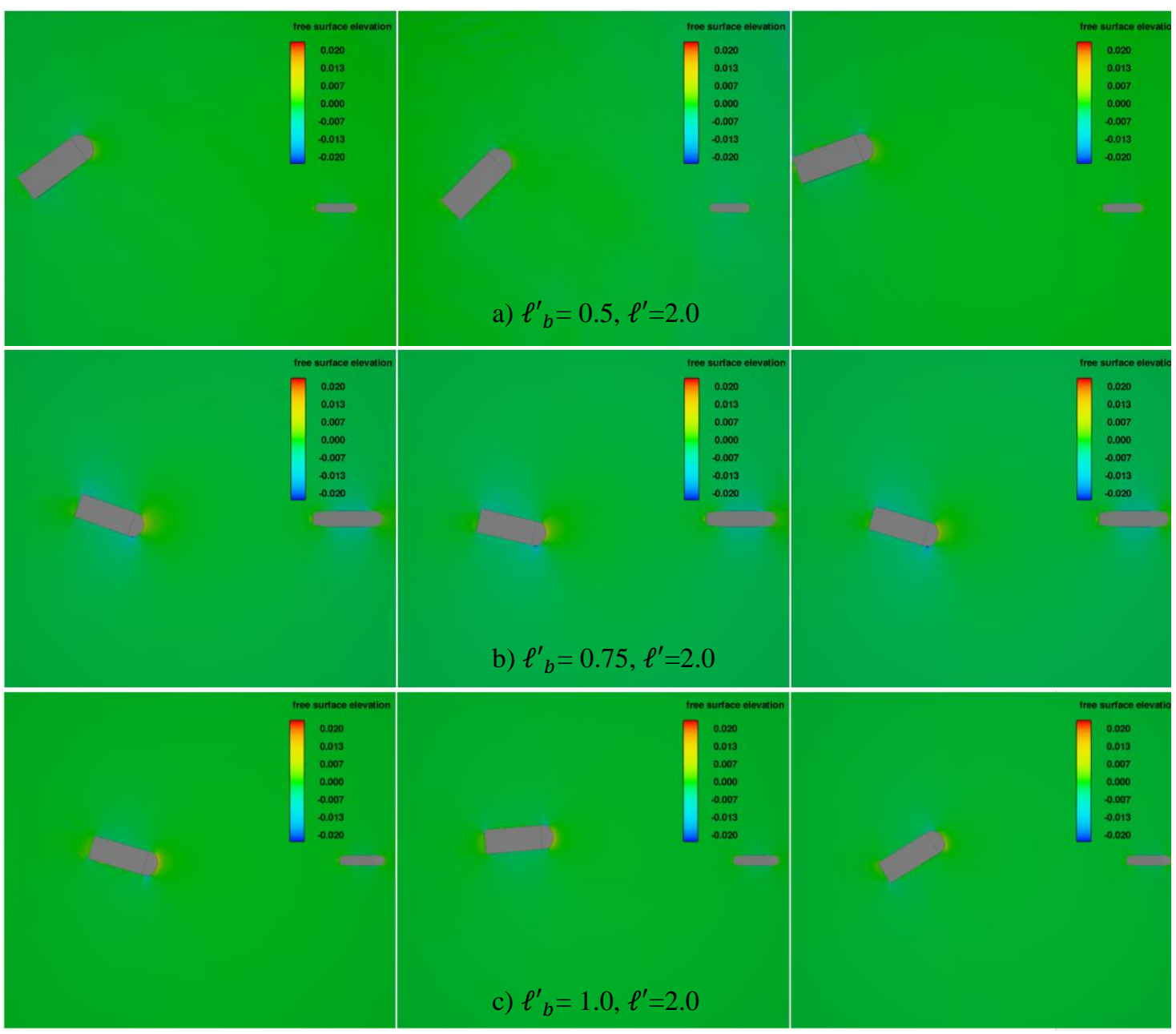

Figure 8. Free surface elevation, $\ell^{\prime}{ }_{b}=0.5$ (a), $\ell^{\prime}{ }_{b}=0.75$ (b), $\ell^{\prime}{ }_{b}=1.0$ (c)

$$
\ell^{\prime}=2.0, V s=0.413 \mathrm{~m} / \mathrm{s}
$$




\section{CONCLUSIONS}

The computational fluid dynamics analysis on the course stability of a ship's towing system was successfully performed using the Flow3D version 10.1 software. The effects of different towline lengths and tow point locations have been appropriately investigated. The simulation results are drawn as follows:

- The increase of towline length $\left(\ell^{\prime}\right)$ from 1.0 up to 3.0 was significant in improving the course stability of the barge as indicated by the decrease in the reduction of sway and yaw motions. However, the towline tension also decreased by $7.8 \%$, which may prevent impulses in the towline that threaten the towing safety.

- The course stability of the towed ship is significantly improved due to the substantial reduction of the sway and yaw motions by $227 \%$ and $328 \%$ as the tow point $\left(\ell_{b}^{\prime}\right)$ was increased from 0.5 to 0.75 and from 0.75 to 1.0 , respectively. Concurrently, this resulted in the sufficient reduction of towline tension by $71.6 \%$ as the tow point was changed from $\ell^{\prime}{ }_{b}=0.5$ to 1.0 .

In general, the increase in tow point had resulted in better course stability of towing compared to increases in towline ones. Correspondingly, these CFD results are useful as preliminary prediction for the course stability of the towing, which deals with navigation safety during towing operations.

\section{ACKNOWLEDGMENT}

The authors would like to thank Ministry of Higher Education (MOHE)-Malaysia for the financial Research Grant VOT. 59414.

\section{REFERENCES}

[1] Fitriadhy A, Yasukawa H, Maimun A. Theoretical and Experimental Analysis of a Slack Towline Motion on Tug-towed Ship during Turning. Ocean Engineering. 2015;99:95106.

[2] Yan S, Huang G. Dynamic Performance of Towing System-Simulation and Model Experiment. OCEAN1996.

[3] Lee M-L. Dynamic Stability of Nonlinear Barge-towing System. Applied Mathematical Modelling. 1989;13:693-701.

[4] Fitriadhy A, Yasukawa H. Course Stability of a Ship Towing System. Ship Technology Research. 2011;58:4-23.

[5] Fitriadhy A, Yasukawa H, Yonedac T, Kohd K, Maimund A. Analysis of an Asymmetrical Bridle Towline Model to Stabilise Towing Performance of a Towed Ship. Jurnal Teknologi (Sciences \& Engineering). 2014;66:151-6.

[6] Fitriadhy A, Yasukawa H, Nik WBW, Bakar AA. Numerical Simulation of Predicting Dynamic Towline Tension on a Towed Marine Vehicle. In: International Conference on Ships and Offshore Structures ICSOS 2016. Hamburg, Germany; 2016.

[7] Yasukawa H, Hirono T, Nakayama Y, Koh K. Course Stability and Yaw Motion of a Ship in Steady Wind. Journal of Marine Science and Technology. 2012;17:291-304.

[8] Fitriadhy A, Yasukawa H, Koh K. Course Stability of a Ship Towing System in Wind. Ocean Engineering. 2013;64:135-45.

[9] Sinibaldi M, Bulian G. Towing Simulation in Wind Through a Nonlinear 4-DOF Model: Bifurcation Analysis and Occurrence of Fishtailing. Ocean Engineering. 2014;88:366-92.

[10] Varyani K, Barltrop N, Clelland D, Day A, Pham X, Van Essen K, et al. Experimental Investigation of the Dynamics of a Tug Towing a Disabled Tanker in Emergency Salvage 
Operation. International Conference on Towing and Salvage Disabled Tankers2007. p. $117-25$.

[11] Kume K, Hasegawa J, Tsukada Y, Fujisawa J, Fukasawa R, Hinatsu M. Measurements of Hydrodynamic Forces, Surface Pressure, and Wake for Obliquely Towed Tanker Model and Uncertainty Analysis for CFD Validation. Journal of Marine Science and Technology. 2006;11:65-75.

[12] FLOW-3D 10.1.1 User Manual: Flow Science Inc.; 2013.

[13] Talaat WM, Hafez K, Banawan A. A CFD Presentation and Visualization For a New Model that Uses Interceptors to Harness Hydro-energy at the Wash of Fast Boats. Ocean Engineering. 2017;130:542-56.

[14] Franke Rt, Rodi W. Calculation of Vortex Shedding Past a Square Cylinder with Various Turbulence Models. Turbulent Shear Flows 8: Springer; 1993. p. 189-204.

[15] Wu C-S, Zhou D-C, Gao L, Miao Q-M. CFD Computation of Ship Motions and Added Resistance for a High Speed Trimaran in Regular Head Waves. International Journal of Naval Architecture and Ocean Engineering. 2011;3:105-10.

[16] Saad I, Bari S. CFD Investigation of In-cylinder Air Flow to Optimize Number of Guide Vanes to Improve ci Engine Performance using Higher Viscous Fuel. International Journal of Automotive and Mechanical Engineering. 2013;8:1096.

[17] Lam S, Shuaib N, Hasini H, Shuaib N. Computational Fluid Dynamics Investigation on the Use of Heat Shields for Thermal Management in a Car Underhood. 2012:785.

[18] Zan U, Yasukawa H, Koh K, Fitriadhy A. Model Experimental Study of a Towed Ship's Motion.

\section{NOMENCLATURE}

$\ell_{b}^{\prime}=\ell_{b} / L \quad$ Ratio of tow point distance to length of barge with respect to her center of gravity

$\ell^{\prime}=\ell / L \quad$ Ratio of towline length with respect to length of barge

2B Barge

CFD Computational Fluid Dynamics

RANS Reynolds-Averaged Navier-Stokes equation

VOF Volume of Fluid method

GMO General moving object

FAVOR Fractional Area-Volume Obstacle Representation 